\title{
Age-related changes in shock absorption capacity of the human spinal column
}

This article was published in the following Dove Press journal:

Clinical Interventions in Aging

\author{
Grażyna Brzuszkiewicz- \\ Kuźmicka' \\ Jan Szczegielniak ${ }^{2}$ \\ Dawid Bączkowicz ${ }^{2}$ \\ 'Department of Rehabilitation, \\ Academy of Physical Education in \\ Warsaw, Warsaw, Poland; ${ }^{2}$ Faculty of \\ Physical Education and Physiotherapy, \\ Institute of Physiotherapy, Opole \\ University of Technology, Opole, \\ Poland
}

\begin{abstract}
Background: The spinal column possesses shock absorption properties, mainly provided by the intervertebral discs. However, with the process of senescence, all structures of the spine, including the discs, undergo degenerative changes. It may lead to alteration of the mechanical properties of the spinal motion segment and diminished capacity for vibration attenuation.

Objective: The objective of this study was to investigate the age-related changes in shock absorption properties of the spine.

Patients and methods: A total of 112 individuals divided into three groups according to age (third, fifth, and seventh decades of life) were enrolled in this study. The transmissibility of vibrations through the spine was measured in a standing position on a vibration platform by accelerometers mounted at the levels of S2 and C0. Registered signals were described using four parameters: VMS (variability), peak-to-peak amplitude (PPA), and spectral activity in two bands F2 (0.7-5 Hz) and F20 (15-25 Hz). Results: In all age groups, signals registered at $\mathrm{C} 0$ were characterized by significantly lower values of VMS, PPA, and F20, when compared to level S2. Simultaneously, the parameter F20 significantly differed among all age groups when C0 vibrations were analyzed: $2.43 \pm 1.93$, $5.02 \pm 3.61$, and $10.84 \pm 5.12$ for the third, fifth, and seventh decades of life, respectively.

Conclusion: The human spinal column provides vibration attenuation; however, this property gradually declines with the aging process.
\end{abstract}

Keywords: vibration transmissibility, amortization, attenuation, senescence process, intervertebral disc

\section{Background}

Functions of the human spine include supporting the body's weight, facilitating movement and flexibility, and protecting other structures in the vulnerable spinal cord from injury. ${ }^{1}$ Along with this, the spinal column possesses shock absorption abilities - it attenuates tremors and vibrations that occur in daily life activities; for example, during gait, each impact of the heel with the ground produces transient waves that propagate up throughout the body. ${ }^{2}$ The intervertebral disc (IvD) is postulated to be the main spinal structure responsible for transfer of the compressive forces between adjacent vertebrae and allowing energy dissipation. With the nucleus behaving like a pressured cylinder, the disc is the main shock absorber of mechanical stresses transmitted during motions from the lower limbs to the skull and brain. ${ }^{3}$

With senescence, all structures of the spinal column, including the IvD, undergo degenerative changes. ${ }^{46}$ The literature suggests that the age-related changes of the IvD and surrounding structures lead to alteration of the mechanical properties of the spinal motion segment. A trend toward spinal stiffening with increasing degeneration has been observed in most studies, although conclusive studies regarding some aspects are lacking. ${ }^{7,8}$ However, the limit between IvD aging and pathological abnormalities is \footnotetext{
Faculty of Physical Education and Physiotherapy, Institute of Physiotherapy, Opole University of Technology, 76 Prószkowska Street, 45-758 Opole, Poland Email d.baczkowicz@po.opole.pl
}

Correspondence: Dawid Bączkowicz 
absolutely indistinct and has been recognized as such since the start of morphological studies on the IvD. ${ }^{9}$ Therefore, as previously suggested, it would be useful to study how the physiological age-related changes within the spine column affect its shock absorption function. ${ }^{2}$

Unfortunately, in all static imaging methods such as X-ray or magnetic resonance imaging (MRI), mainly structural changes are observed, and for the analysis of spine shock absorption properties, these methods are unsuitable. ${ }^{10}$ Other techniques focused on function assessment can be difficult to interpret due to the nonspecific application (eg, electromyography) or are problematic to employ due to cost, access, and invasiveness (eg, fluoroscopy). Given the above, there is a significant inability to quantify shock absorption properties using diagnostic methods commonly applied in health care. ${ }^{11}$

To fill this void, several authors have identified established engineering techniques used in evaluating mechanical assemblies and adapted them for use in the analysis of human locomotor system function. ${ }^{11-14}$ It seems that the spine shock absorption properties can be directly expressed in the frequency domain as the transmissibility of vibration through the spinal column. ${ }^{15}$ These vibrations can be measured with accelerometers attached to the skin over the spine bony prominence, which has been previously validated against pins inserted directly into the bone, with promising results. ${ }^{16}$ However, currently there are no strict guidelines for the use of specific brands and models of accelerometers for the measurement of vertical human vibration transmissibility. ${ }^{2}$

There have been few studies on the transmission of vibrations through the human body, and through the axial skeleton. ${ }^{17-19}$ It has been reported that the spine transmitted more than $50 \%$ of the vibration received at the sacrum. ${ }^{2}$ In turn, Helliwell et $\mathrm{al}^{20}$ and Smeathers ${ }^{21}$ over 20 years ago reported that the normal spinal column has the capability to absorb vibrations with a frequency greater than $15 \mathrm{~Hz}$. Moreover, it was also demonstrated that signals registered from healthy subjects possess a different frequency domain in comparison to patients with spine disorders (eg, ankylosing spondylitis). ${ }^{21}$ However, the influence of senescence on the human spine shock absorption capacity has not been analyzed before. Hence, the aim of this study was to measure the in vivo vibration transmissibility of the spinal column using skin-mounted accelerometers in healthy subjects in a wide range of age groups. This investigation may help to expand the knowledge about the amortization function of the human spine and the age-related changes in its shock absorption properties.

\section{Patients and methods Study population}

A total of 112 healthy subjects (47 males and 65 females) in three age categories (third decade, 20-29 years old; fifth decade, 40-49 years old; seventh decade, 60-69 years old) were enrolled in the study. Based on the questionnaire and medical interviews, to prevent any artifacts and biased results originating from the influence of factors not associated with aging, individuals with spinal column disorders, postural defects, osteoarthritis, underweight or obesity (with a body mass index less than $18.5 \mathrm{~kg} / \mathrm{m}^{2}$ or greater than $30 \mathrm{~kg} / \mathrm{m}^{2}$, respectively), or other neurological or musculoskeletal disorders were excluded from the study. For the sake of patients' safety, patients with osteopenia/osteoporosis and endoprosthesis were not included in the study. Analyzed age groups did not differ significantly in anthropometric parameters; their detailed characteristics are given in Table 1.

Signed informed consent was obtained from all tested persons, and the rights of subjects were protected. The project was approved by the Opole Voivodship Ethics Committee.

\section{Vibration platform and accelerometers}

Assessment of spine shock absorption properties was performed by measuring the transmission of vibrations through the human body, generated by a vibration platform developed for use in whole-body vibration training (Figure 1). The used platform allowed generation of complex sine-wave vertical vibrations of frequency $2 \mathrm{~Hz}$ and $10 \mathrm{~mm}$ amplitude, with simultaneously superimposed vibrations of $20 \mathrm{~Hz}$ and $2 \mathrm{~mm}$ amplitude, produced by two servo-controlled electrodynamic vibrators, with a total electrical power of $0.8 \mathrm{~kW}$.

Table I Characteristics of assessment groups

\begin{tabular}{llllll}
\hline $\begin{array}{l}\text { Analyzed } \\
\text { groups }\end{array}$ & $\begin{array}{l}\text { Number of } \\
\text { males/females }\end{array}$ & $\begin{array}{l}\text { Age (years), } \\
\text { mean (SD) }\end{array}$ & $\begin{array}{l}\text { Height (cm), } \\
\text { mean (SD) }\end{array}$ & $\begin{array}{l}\text { Weight (kg), } \\
\text { mean (SD) }\end{array}$ & $\begin{array}{l}\left.\text { BMI (kg/m }{ }^{2}\right), \\
\text { mean (SD) }\end{array}$ \\
\hline Third $(n=37)$ & $16 / 21$ & $24.2(2.6)$ & $170.1(9.1)$ & $68.8(12.3)$ & $23.8(3.7)$ \\
Fifth $(n=39)$ & $17 / 22$ & $46.1(2.3)$ & $169.5(8.4)$ & $69.9(10.9)$ & $24.6(3.1)$ \\
Seventh $(n=36)$ & $14 / 22$ & $64.7(2.9)$ & $168.2(8.8)$ & $70.7(I 1.4)$ & $25.3(3.5)$ \\
\hline
\end{tabular}


e

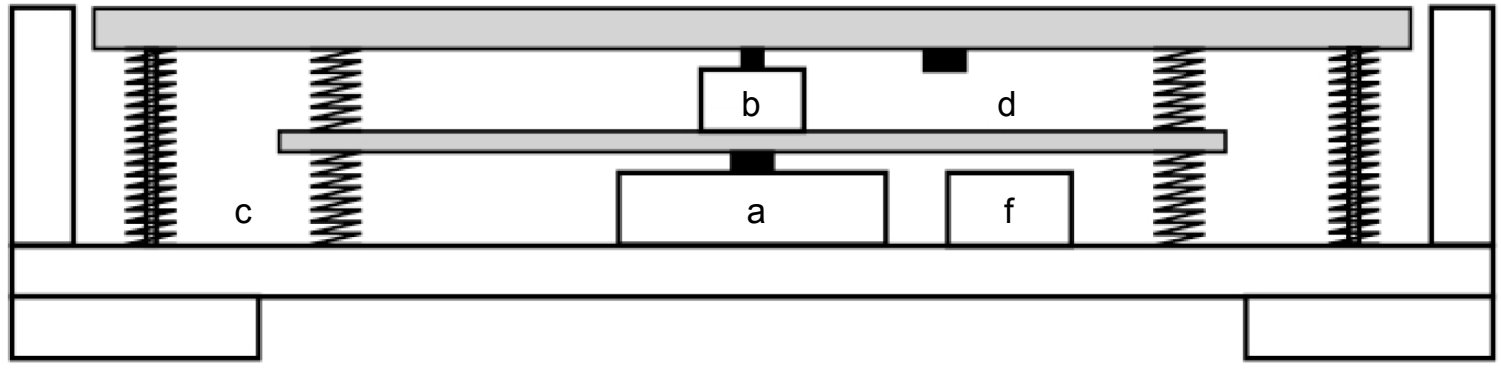

Figure I Scheme of vibration platform (a: $2 \mathrm{~Hz}$ electrodynamic vibrator; b: $20 \mathrm{~Hz}$ electrodynamic vibrator; c: compression springs; d: accelerometer for control; e: plate of platform; f: microcontroller).

The control system automatically allowed adjustment of the vibration amplitude and its frequency to the required values, based on data acquired from the internal accelerometer. The dimensions of the platform with handrails are as follows: $130 \times 70 \times 120 \mathrm{~cm}$, for length, width, and height, respectively; the total mass is approximately $120 \mathrm{~kg}$.

For vibration transmission acquisition, two single-axis piezoelectric acceleration sensors were used: model 4513B-002 with a multichannel Nexus conditioning amplifier (Brüel \& Kjær Sound \& Vibration Measurement A/S, Nærum, Denmark). A computer equipped with a measuring card type CH 3160 (Acquitek, Paris, France) and specialized AcquiFlex software were used for registration of the signals (Figure 2).

\section{Procedure}

The sensors were put over two locations of the spine. One accelerometer was mounted to the skin by double-sided adhesive tape at the level of the spinous process of the second sacral vertebra (S2) to measure the "input" signals. The second one, which recorded the "output" signal, was mounted by an elastic band at the level of the lambda skull landmark (C0). The accelerometers were aligned with the long axis of the spine as nearly vertical as possible. The $\mathrm{S} 2$ and $\mathrm{C} 0$ were identified by palpation performed by a trained clinician, and the accelerometers were placed by the same clinician.

Subjects were instructed to maintain a comfortable position at the center of the vibration platform with feet shoulderwidth apart, keep their arms by their sides, and look straight ahead at a point on the wall approximately $3 \mathrm{~m}$ away, at eye level. The assessment was performed in the early morning hours, in underwear, without shoes and socks.

\section{Data collection and signal analysis}

After correct positioning of the patient on the platform, the vibration was switched on, and the data acquisition

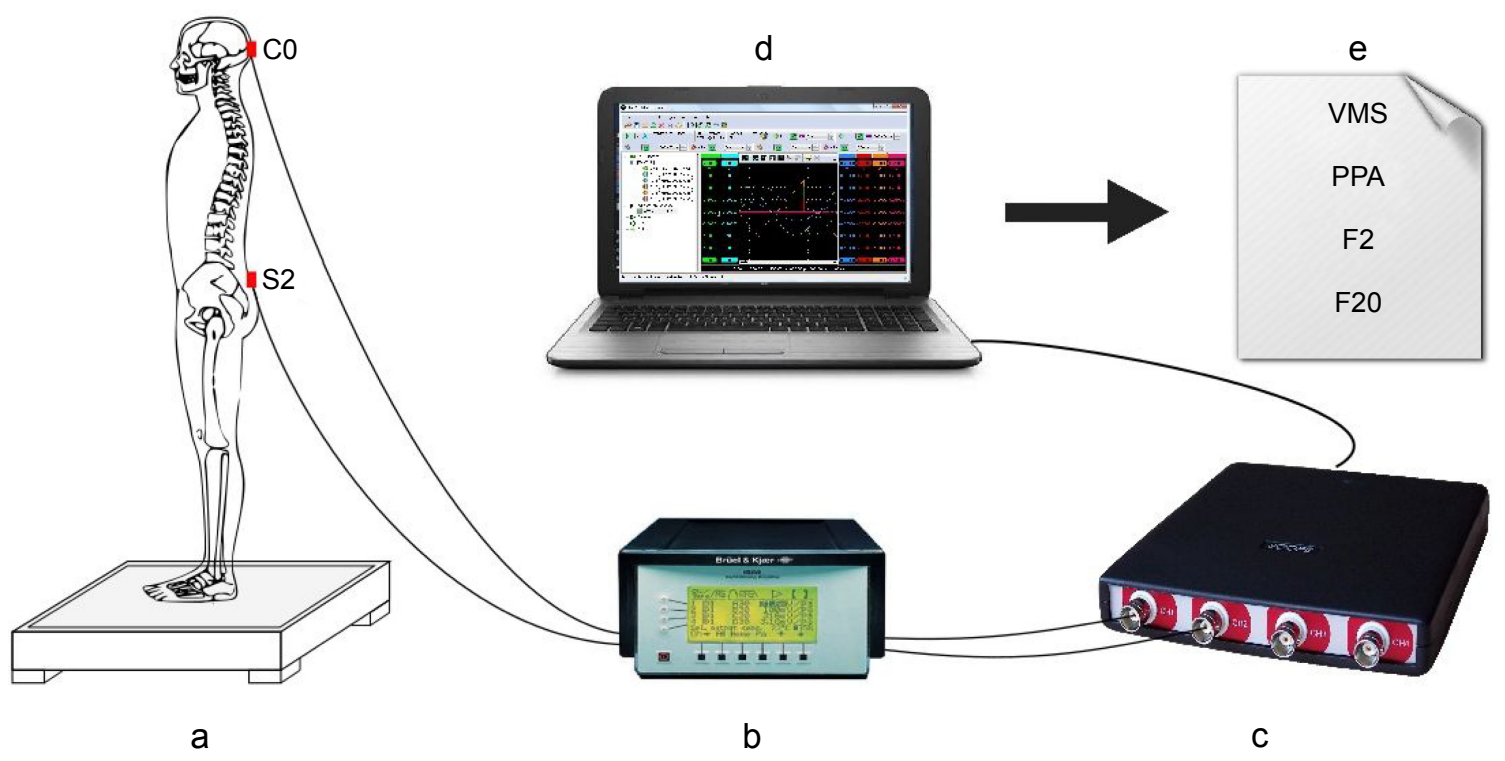

Figure 2 Scheme of measurement stand and equipment (a: vibration platform; b: amplifier; c: measuring analog-to-digital card; d: PC; e: analyzed parameters). Abbreviation: PPA, peak-to-peak amplitude. 
commenced after 10 seconds and lasted 6 seconds. Recording of generated signals was performed in the periodicity between 0.7 and $100 \mathrm{~Hz}$ with a sampling rate of $1 \mathrm{kHz}$. Each result was low-pass filtered according to the $50 \mathrm{~Hz}$ threshold. The obtained signals ranged from 0.7 to $50 \mathrm{~Hz}$ and are described using four parameters. The variability of the recorded signals was assessed by computing the mean-squared values of an obtained signal in fixed-duration segments of $5 \mathrm{~ms}$ each, and then computing the variance of the values of the parameter over the entire duration of the signal (VMS). Moreover, for signal amplitude analysis, the peak-to-peak amplitude (PPA) parameter was used, calculated by the difference between the highest amplitude value and the lowest amplitude value. For assessment of the signal frequency characteristics, the spectral activity was analyzed by summing the spectral power of the recorded signal in two bands: F2 (0.7-5 Hz) and F20 (15-25 Hz). All data were analyzed using custom-made scripts in MATLAB (R2010b; MathWorks Inc.).

\section{Statistical analysis}

Demographic and anthropometric characteristics of analyzed groups were presented as descriptive statistics (mean and $\mathrm{SD})$, and the Mann-Whitney $U$-test was used to evaluate differences between them. Normality of the distribution was assessed with the Shapiro-Wilk test. Because of skewed distribution of F2 and F20 parameter values, they were analyzed after logarithmic transformation. Evaluation of all dependent variables was performed with analysis of variance, and then for post hoc comparisons, the Tukey test for unequal sample sizes was used. For correlation analysis between anthropometric data and VMS, PPA, F2, and F20 parameter values, Pearson's $r$ test was performed. The level of significance was set at $p<0.05$. Statistical analysis was performed using Statistica v.12 (StatSoft, Inc., Tulsa, OK, USA).

\section{Results}

The mean values of signal parameters registered from 112 individuals in three age-category groups are presented in Table 2. When values of VMS, PPA, and F20 parameters recorded from S2 and C0 were compared, differences between these two levels were found in all age-category groups (Table 2). All signals registered from $\mathrm{C} 0$ were characterized by significant lower variability, amplitude, and the spectral activity in the range of 15-25 Hz, when compared to S2 level. Only the F2 parameter did not differentiate the signals between "input" and "output", due to the very similar spectral activity from 0.7 to $5 \mathrm{~Hz}$ in all considered groups.

In Figure 3, representative signal courses registered from S2 and C0 levels for individuals in the third, fifth, and seventh decades of life are shown. It can be observed that the signal registered from S2 in all cases had a similar course (Figure $3 \mathrm{~A}-\mathrm{C}$ ). In contrast, the signal registered from the $\mathrm{C} 0$ level differed between particular representatives of groups (Figure 3D-F). It can be seen that the signal representative for the third-decade group (Figure 3D) exhibited a smooth signal sinusoidal wave of $2 \mathrm{~Hz}$ frequency. In the fifth-decade group (Figure 3E), additional low oscillations of $20 \mathrm{~Hz}$ occurred in the signal course, intensifying in the seventh-decade group (Figure 3F).

These observations are confirmed by the mean values of VMS, PPA, F2, and F20 parameters (Table 2). The statistical analysis did not indicate any differences in these parameters between age groups, when analyzed for S2 level. Meanwhile, when spectral activity of $\mathrm{C} 0$ vibrations was analyzed, the F20 parameter showed significant variation among all age groups - the values increase geometrically with age. Similarly, we observed a significant age-related increase of PPA values describing the amplitude of $\mathrm{C} 0$ vibrations, but only when comparing the youngest and the oldest age groups.

The characteristics of signals reflecting the vibrations at the $\mathrm{C} 0$ level are also illustrated as distributions of the frequency spectrum in Figure 4. While the power spectrum density in $\sim 5 \mathrm{~Hz}$ bandwidth in the analyzed groups was similar, differences in the power spectral density in the $\sim 20 \mathrm{~Hz}$ bandwidth were clearly observed between all three groups.

Table 2 Values of analyzed parameters and statistical differences between particular decades of life

\begin{tabular}{|c|c|c|c|c|c|c|c|c|}
\hline \multirow{2}{*}{$\begin{array}{l}\text { Analyzed } \\
\text { groups }\end{array}$} & \multicolumn{2}{|c|}{ VMS (V), mean $\pm S D$} & \multicolumn{2}{|c|}{ PPA (V), mean \pm SD } & \multicolumn{2}{|c|}{ F2 $\left(V^{2} / H z\right)$, mean $\pm S D$} & \multicolumn{2}{|c|}{ F20 $\left(V^{2} / H z\right)$, mean $\pm S D$} \\
\hline & Sacrum & Occiput & Sacrum & Occiput & Sacrum & Occiput & Sacrum & Occiput \\
\hline Third (20-29) & $0.64 \pm 0.31$ & $0.21 \pm 0.13$ & $1.42 \pm 1.53$ & $0.9 I \pm 0.64$ & $1.62 \pm 0.82$ & $1.57 \pm 0.82$ & II. $.47 \pm 5.02$ & $2.43 \pm 1.93$ \\
\hline Fifth (40-49) & $0.66 \pm 0.35$ & $0.21 \pm 0.14$ & $1.47 \pm 1.62$ & $0.98 \pm 0.73$ & $1.64 \pm 0.79$ & $1.58 \pm 0.87$ & $12.5 \mid \pm 6.14$ & $5.02 \pm 3.61$ \\
\hline Seventh (60-69) & $0.7 I \pm 0.42$ & $0.23 \pm 0.18$ & $1.58 \pm 1.64$ & $1.14 \pm 0.70$ & $1.65 \pm 0.96$ & $1.60 \pm 1.14$ & $13.03 \pm 7.66$ & $10.84 \pm 5.12$ \\
\hline \multicolumn{9}{|l|}{$p$-values } \\
\hline Third vs fifth & 0.143 & 0.387 & 0.397 & 0.114 & 0.190 & 0.485 & 0.093 & 0.012 \\
\hline Third vs seventh & 0.052 & 0.178 & 0.060 & 0.037 & 0.398 & 0.217 & 0.051 & 0.001 \\
\hline Fifth vs seventh & 0.196 & 0.215 & 0.105 & 0.092 & 0.264 & 0.269 & 0.127 & 0.006 \\
\hline
\end{tabular}

Note: Bold values are statistically significant $(p<0.05)$.

Abbreviation: PPA, peak-to-peak amplitude. 
A

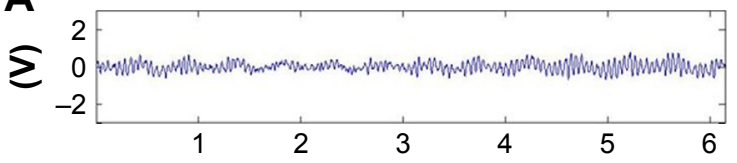

(s)

B

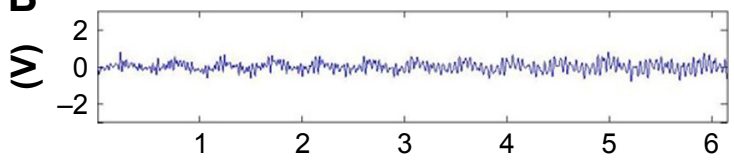

(s)

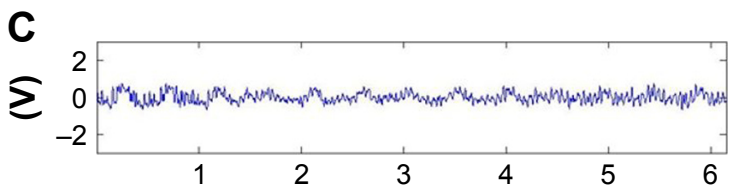

(s)

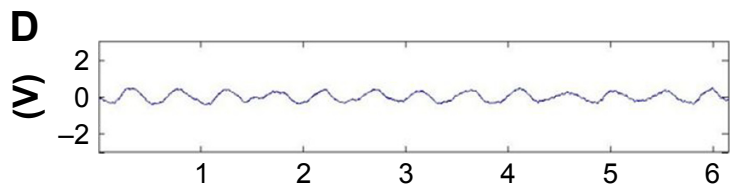

(s)

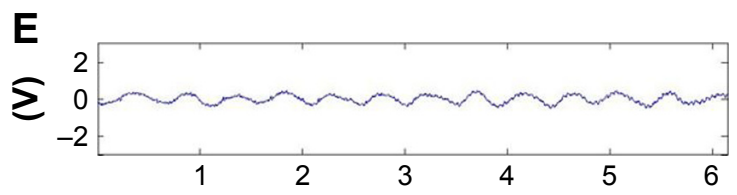

(s)

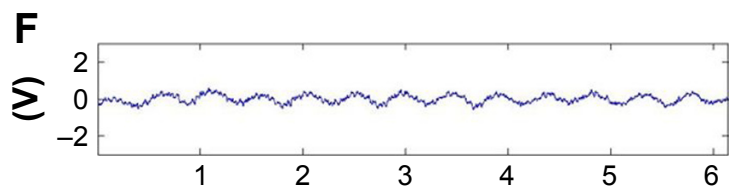

(s)

Figure 3 Course of the signals registered on the S2 level: representatives for individuals in the third decade of life (A), fifth decade of life (B), and seventh decade of life (C). Course of the signals registered on the C0 level: representatives for individuals in the third decade of life (D), fifth decade of life (E), and seventh decade of life (F).

In addition, significant correlations between values of analyzed parameters and anthropometric data were found. The values of PPA and F20 parameters measured at the $\mathrm{C} 0$ level were negatively correlated with height of participants, but only in the third-decade group ( $r=-0.39, p=0.04$ and $r=-0.53, p=0.01$, respectively).

\section{Discussion}

The purpose of the present study was to investigate the age-related changes in shock absorption properties of the human spinal column. The analysis relied on the assessment of vibration transmissibility through the spine, measured by skin-mounted accelerometers. Our hypotheses and the results of other authors indicated that the healthy spine is able to attenuate frequency components mainly above $15 \mathrm{~Hz} .^{20,21}$ However, it was also previously suggested that the various daily physical activities may generate vibrations in the lower

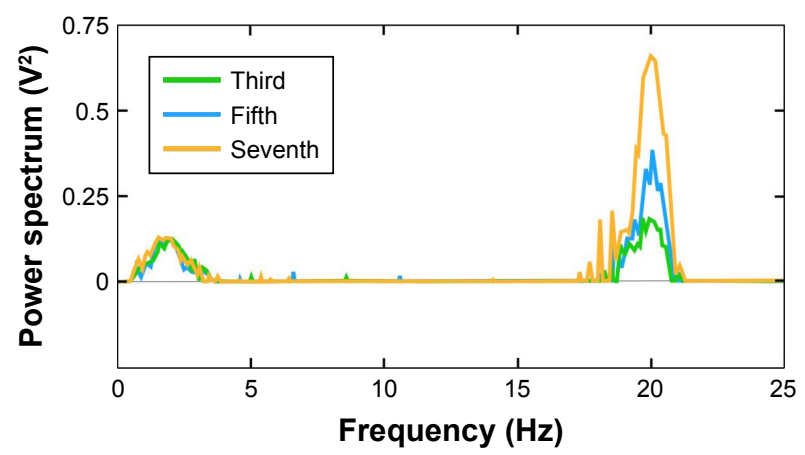

Figure 4 Power spectrum distribution in all signals recorded from the $\mathrm{C} 0$ level for particular age groups. spectrum of frequencies $(0.5-4 \mathrm{~Hz})$ and that during daily life or sport physical activities, the human body is exposed to complex waves rather than simple, isolated sine waves. ${ }^{2}$ Therefore, we analyzed the spine's capability of attenuation of combined vibrations, consisting of a sinusoidal waveform with $2 \mathrm{~Hz}$ frequency and $10 \mathrm{~mm}$ amplitude as well as $20 \mathrm{~Hz}$ frequency and $2 \mathrm{~mm}$ amplitude.

The results presented herein confirmed that the spinal column allows for energy dissipation and provides vibration absorption. This is clearly visible for vibration components of $20 \mathrm{~Hz}$, which were attenuated by $50 \%$ on average (F20 parameter), when all patients were analyzed together. This phenomenon was expected according to the previous studies and is elucidated by the biomechanical properties of the IvD and its viscoelastic behavior. ${ }^{22,23}$ In turn, when shock absorption properties of vibrations in bandwidths of $2 \mathrm{~Hz}$ frequency and $10 \mathrm{~mm}$ amplitude (F2 parameter) were analyzed, we found that in particular age groups, the structures of the spinal column from the sacrum to the occiput transfer $97 \%$ of vibrations, regardless of age. Our observations may be explained by the results of Helliwell et al, ${ }^{20}$ who reported that in healthy subjects vibration transmissibility was attenuated at frequencies above $15 \mathrm{~Hz}$, but below $13 \mathrm{~Hz}$ the transmissibility can be enhanced due to muscular contraction. Similarly, Baig et al ${ }^{24}$ suggested that frequencies of $2-4 \mathrm{~Hz}$ may induce greater muscle activity, leading to spinal stiffening, due to dynamic stabilization. However, in our study, the muscle activity was not evaluated, and it is difficult to determine whether the lack of absorption of vibration of $2 \mathrm{~Hz}$ 
is associated with viscoelastic characteristics of the IvDs or dynamic stabilization provided by muscle tension. ${ }^{25}$ Kiiski et $\mathrm{al}^{19}$ reported that the vibration-induced accelerations can increase at frequencies $<20 \mathrm{~Hz}$ because of body segment resonances. Anyway, this result is consistent with the view that spine shock absorption is a complex process and that the spine dissipates energy preferentially and does not act as a simple shock absorber in the direction of the spinal axis. ${ }^{26}$

Furthermore, we found that the aging process is accompanied by reduced spine shock-absorbing capability. It is difficult to compare our results to previous studies, as to the best of our knowledge no prior research has investigated the influence of the aging process on the spine shock absorption function. Our results directly showed age-related diminished possibilities of attenuation of $20 \mathrm{~Hz}$ vibrations, observed as a significant increase of the F20 parameter values measured at $\mathrm{C} 0$, with successive decades of life. When we analyzed spectral power in the bandwidth from 15 to $25 \mathrm{~Hz}$, for sexagenarians, we noted twofold and fourfold higher levels of vibrations measured at the skull, when compared to the quadragenarians and the vicenarians, respectively. We postulate that this phenomenon mainly results from agerelated degenerative changes in the spinal column structures, responsible for shock absorption. It was reported that with the physiological aging process the alterations in the extracellular matrix of the IvD occur through modification in the synthesis of type II collagen to type I collagen, and reduction of aggrecan synthesis in the nucleus pulposus. This process can extend to and affect the annulus fibrosus, consequently reducing the intervertebral space. ${ }^{9}$ Similar changes occur in the end plates, which may have consequences for the nutritional supply and hydration of the IvD. ${ }^{22,27}$ Although the mechanical effect of these degenerative changes is not fully understood, it appears that alterations of the tissue properties of the IvD, including dehydration and reorganization of the nucleus and stiffening of the annulus fibrosus, cause the IvD to be less able to adjust to compression. ${ }^{7,8,28,29}$ However, it should be noted that the observed age-related increase of the vibration level measured at the occiput could also be a partial consequence of the process of senescence of the overall musculoskeletal system, not only the spinal column. This thesis may be supported by the observed trend of an age-associated increase of all analyzed parameters, and near statistically significant differences between the third and seventh groups in VMS, PPA, and F20 parameter values measured at the S2 level. Thus, it appears that the reduced muscle strength, stiffer tendons, and degenerative changes within lower limb joints typical for aging may be an additional, relevant factor responsible for diminished vibration absorption in the elderly.
Moreover, in this study, we analyzed the relationships between anthropometric data of participants and spine shockabsorbing capacity. In particular, we observed negative correlations between body height and the spectral power in the bandwidth from 15 to $25 \mathrm{~Hz}$ (F20 parameter) measured at the occiput. However, these relations were present only in the third group. We propose that the observed phenomenon may be associated with the fact that a longer spine column possesses better damping properties than a shorter one, but due to the age-related changes within the IvD and its loss of height, differences in capability of vibration attenuation decline. It should also be considered that the reduction in height of the IvD directly affects the adjacent vertebrae; it can lead to an increase of more than $50 \%$ of the compressive force on the lumbar spine being resisted by the neural arch. ${ }^{30}$ Thus, it cannot be excluded that the observed disturbances of vibration attenuation are also associated with age-related changes in other structures of the spinal motion segment, including zygapophysial joints. ${ }^{5,27}$ Moreover, it seems that the shape of the spinal curvatures also may significantly affect the amortization function. ${ }^{19,31}$ It was suggested that the spines of patients with decreased curvatures (decreased lordosis or axially extended spines) possess decreased capacity of shock attenuation. ${ }^{32}$

Due to this, a limitation of our study is unknown status of spinal structures (IvD and zygapophysial joints), not analyzed by a suitable imaging method (eg, MRI). We also did not consider the effect of the shape of the spinal curves on the obtained results. Moreover, some constraints are related to the use of skin-mounted accelerometers, despite the fact that every effort was made to ensure that the accelerometers were mounted identically on all subjects. It should be taken into account that certain anthropometric characteristics related to interpersonal anatomical differences or age-related changes not associated with the spine as well as differences in sensor mounting methods could have a slight impact on the obtained results. Therefore, further research should include direct evaluation of spinal structures and should focus on anthropometric characteristics (including the shape of curvatures of the vertebral column, body mass index, muscle strength, and muscle tension) to establish the real relationship between these factors and spine vibration transmissibility. Moreover, repeatability of the analysis of the vibration attenuation is not recognized, and it seems that in subsequent studies test-retest reliability is necessary to confirm the clinical usefulness of this method.

\section{Conclusion}

Our findings seem to extend the knowledge of the amortization function of the human spine. Although our data were obtained with skin-mounted accelerometers and can be considered 
indicative only, we showed that the spinal column allows for energy dissipation and provides vibration attenuation, but these properties gradually decrease with age. The diminished capability of shock absorption can be explained by age-related changes in the structures of the spinal motion segment, mainly the IvDs.

\section{Disclosure}

The authors report no conflicts of interest in this work.

\section{References}

1. Newell N, Little JP, Christou A, Adams MA, Adam CJ, Masouros SD. Biomechanics of the human intervertebral disc: a review of testing techniques and results. J Mech Behav Biomed Mater. 2017;69:420-434.

2. Morgado Ramírez DZ, Strike S, Lee RY. Measurement of transmission of vibration through the human spine using skin-mounted inertial sensors. Med Eng Phys. 2013;35(5):690-695.

3. Izzo R, Guarnieri G, Guglielmi G, Muto M. Biomechanics of the spine. Part I: spinal stability. Eur J Radiol. 2013;82(1):118-126.

4. Vergroesen PP, Kingma I, Emanuel KS, et al. Mechanics and biology in intervertebral disc degeneration: a vicious circle. Osteoarthritis Cartilage. 2015;23(7):1057-1070.

5. Del Grande F, Maus TP, Carrino JA. Imaging the intervertebral disk: age-related changes, herniations, and radicular pain. Radiol Clin North Am. 2012;50(4):629-649.

6. Wang F, Cai F, Shi R, Wang XH, Wu XT. Aging and age related stresses: a senescence mechanism of intervertebral disc degeneration. Osteoarthritis Cartilage. 2016;24(3):398-408.

7. Galbusera F, van Rijsbergen M, Ito K, Huyghe JM, Brayda-Bruno M, Wilke HJ. Ageing and degenerative changes of the intervertebral disc and their impact on spinal flexibility. Eur Spine J. 2014;23 Suppl 3: S324-S332.

8. Wang F, Cai F, Shi R, Wang XH, Wu XT. Aging and age related stresses: a senescence mechanism of intervertebral disc degeneration. Osteoarthritis Cartilage. 2016;24(3):398-408.

9. Baptista JS, Fontes RB, Liberti EA. Aging and degeneration of the intervertebral disc: review of basic science. Coluna/Columna. 2015;14(2): 144-148.

10. Neubert A, Fripp J, Engstrom C, Gal Y, Crozier S, Kingsley MI. Validity and reliability of computerized measurement of lumbar intervertebral disc height and volume from magnetic resonance images. Spine J. 2014; 14(11):2773-2781.

11. Kawchuk GN, Hartvigsen J, Edgecombe T, Prasad N, van Dieen JH. Structural health monitoring (vibration) as a tool for identifying structural alterations of the lumbar spine: a twin control study. Sci Rep. 2016; 6:22974

12. Bączkowicz D, Majorczyk E. Joint motion quality in chondromalacia progression assessed by vibroacoustic signal analysis. PM R. 2016; 8(11):1065-1071.

13. Bączkowicz D, Majorczyk E, Kręcisz K. Age-related impairment of quality of joint motion in vibroarthrographic signal analysis. Biomed Res Int. 2015;2015:591707.
14. Askarzadeh Z, Moradi H. Multivariable control of transmitted vibrations to the seat model of the human body. Int J Ind Ergonom. 2016; 56:69-83.

15. Mansfield NJ. Impedance methods (apparent mass, driving point mechanical impedance and absorbed power) for assessment of the biomechanical response of the seated person to whole-body vibration. Ind Health. 2005;43(3):378-389.

16. Kitazaki S, Griffin MJ. A data correction method for surface measurement of vibration on the human body. J Biomech. 1995;28(7):885-890.

17. Munera M, Chiementin X, Duc S, Bertucci W. Transmission of wholebody vibration to lower limb during dynamic squat exercise. Comput Methods Biomech Biomed Eng. 2014;17 Suppl 1:148-149.

18. Munera M, Bertucci W, Duc S, Chiementin X. Transmission of whole body vibration to the lower body in static and dynamic half-squat exercises. Sports Biomech. 2016;15(4):409-428.

19. Kiiski J, Heinonen A, Järvinen TL, Kannus P, Sievänen H. Transmission of vertical whole body vibration to the human body. J Bone Miner Res. 2008;23(8):1318-1325.

20. Helliwell PS, Smeathers JE, Wright V. Shock absorption by the spinal column in normals and in ankylosing spondylitis. Proc Inst Mech Eng $H$. 1989;203(4):187-190.

21. Smeathers JE. Measurement of transmissibility for the human spine during walking and running. Clin Biomech (Bristol, Avon). 1989;4(1): 34-40.

22. Zhou Z, Gao M, Wei F, et al. Shock absorbing function study on denucleated intervertebral disc with or without hydrogel injection through static and dynamic biomechanical tests in vitro. Biomed Res Int. 2014; 2014:461724.

23. Inoue N, Espinoza Orías AA. Biomechanics of intervertebral disk degeneration. Orthop Clin North Am. 2011;42(4):487-499.

24. Baig HA, Dorman DB, Bulka BA, Shivers BL, Chancey VC, Winkelstein BA. Characterization of the frequency and muscle responses of the lumbar and thoracic spines of seated volunteers during sinusoidal whole body vibration. J Biomech Eng. 2014;136(10):101002.

25. Feltham MG, van Dieën JH, Coppieters MW, Hodges PW. Changes in joint stability with muscle contraction measured from transmission of mechanical vibration. J Biomech. 2006;39(15):2850-2856.

26. Holmes AD, Hukins DW. Analysis of load-relaxation in compressed segments of lumbar spine. Med Eng Phys. 1996;18(2):99-104.

27. Iorio JA, Jakoi AM, Singla A. Biomechanics of degenerative spinal disorders. Asian Spine J. 2016;10(2):377-384.

28. Stewart DM, Monaco LA, Gregory DE. The aging disc: using an ovine model to examine age-related differences in the biomechanical properties of the intralamellar matrix of single lamellae. Eur Spine J. 2017; 26(1):259-266.

29. Ferguson SJ, Steffen T. Biomechanics of the aging spine. Eur Spine J. 2003;12 Suppl 2:S97-S103.

30. Pollintine P, Przybyla AS, Dolan P, Adams MA. Neural arch load-bearing in old and degenerated spines. J Biomech. 2004;37(2):197-204.

31. Antczak A, Haor B, Głowacka M, Biercewicz M. The role of the nurse in the treatment of back pain. $J$ Neurol Neurosurg Nurs. 2014;3(1): $39-43$.

32. Truszczynska A, Drzal-Grabiec J, Cichosz P, Trzaskoma Z. Measurement of spinal curvatures during sitting on a rehabilitation ball versus stool. Turk J Phys Med Rehab. 2016;62(2):148-155.
Clinical Interventions in Aging

\section{Publish your work in this journal}

Clinical Interventions in Aging is an international, peer-reviewed journal focusing on evidence-based reports on the value or lack thereof of treatments intended to prevent or delay the onset of maladaptive correlates of aging in human beings. This journal is indexed on PubMed Central, MedLine,

\section{Dovepress}

CAS, Scopus and the Elsevier Bibliographic databases. The manuscript management system is completely online and includes a very quick and fair peer-review system, which is all easy to use. Visit http://www.dovepress. com/testimonials.php to read real quotes from published authors. 